\title{
Histometric analysis of alveolar bone regeneration with expanded polytetrafluoroethylene (e-PTFE) and latex membranes
}

\author{
Gustavo Otoboni Molina', Marcelo Tomás de Oliveira², Leonardo Buss', João Davi Faraco Peruchi', \\ Jefferson Ricardo Pereira ${ }^{4}$, Janaina Salomon Ghizoni ${ }^{3}$
}

\author{
1'Department of Periodontology, Dental School, University of Southern Santa Catarina (UNISUL), Tubarão, SC, Brazil \\ ${ }^{2}$ Department of Dental Materials, Dental School, University of Southern Santa Catarina (UNISUL), Tubarão, SC, Brazil \\ ${ }^{3}$ Department of Oral Pathology, Dental School, University of Southern Santa Catarina (UNISUL), Tubarão, SC, Brazil \\ ${ }^{4}$ Department of Prosthodontics, Dental School, University of Southern Santa Catarina (UNISUL), Tubarão, SC, Brazil
}

Received for publication: May 20, 2013 Accepted: August 16, 2013

Correspondence to: Jefferson Ricardo Pereira Rua Recife 200, apto 601, CEP: 88701-420 Bairro Recife, Tubarão, SC, Brasil Phone: +554836471571

Fax: +551436264088 E-mail: jeffripe @ rocketmail.com

\begin{abstract}
Aim: To investigate the amount of connective tissue migrated into the extraction socket using EPTFE and latex membranes. Methods: Seventeen rats were selected and randomly divided into 3 groups: e-PTFE membrane $(n=6)$, Latex membrane $(n=6)$ and Control (no membrane, $\mathrm{n}=5$ ). After extraction of the maxillary right incisor, the animals of the test groups were subjected to alveolar guided bone regeneration (GBR) surgery and received an expanded polytetrafluoroethylene (e-PTFE) and a latex membrane, respectively. Thirty days after surgery, the animals were killed and histometric analysis was done to evaluate the migration of connective tissue. Data were analyzed statistically by one-way ANOVA and multiple-comparison Tukey's test at $5 \%$ significance level. Results: There was statistically significant difference between groups ePTFE and Latex ( $p=0.001)$, and between groups e-PTFE and Control $(p=0.012)$, but no significant difference was found between groups Latex and Control $(p=0.416)$. Conclusions: The ePTFE membrane showed better results and appeared more adequate for GBR therapy, forming a barrier to prevent the migration of connective tissue into the extraction socket. The latex membrane, on the other hand, did not show benefits over the control group.
\end{abstract}

Keywords: bone regeneration, membranes, oral surgery, tooth extraction.

\section{Introduction}

When all attempts maintaining the tooth have failed and extraction of teeth is inevitable, the dentist is faced with the concern of maintaining the height and thickness of the alveolar ridge, which are critical for rehabilitation with implantsupported dentures. Alveolar bone resorption after tooth extraction results in a significant reduction in bone height. The connective tissue can have great influence on osteogenesis during alveolar healing and results in narrowing of the alveolus after approximately one month of extraction, due to local bone resorption. This 
leads to aesthetic and restorative complications, such as decrease of bone volume for future installation of osseointegrated implants ${ }^{1}$.

Periodontal regeneration and bone ridge restoration using physical barriers are well-established procedures in reconstructive surgery. It is possible to find different techniques using physical barriers ${ }^{2-7}$ and the characteristics of the biomaterial and the design of the membrane used in guided tissue regeneration play an important role in obtaining good results ${ }^{8}$.

Expanded polytetrafluoroethylene (e-PTFE) membranes have been the standard materials for clinical treatment with guided bone regeneration (GBR), achieving good results when used as mechanical barriers covering sites of extraction ePTFE is a polymer with high stability in biological systems, which provides better tissue organization, infection resistance and no induction of inflammatory reactions ${ }^{1}$. e-PTFE membranes are used as mechanical barriers to protect the blood clot and allow bone cells to be selected to repopulate the bone defect, preventing the epithelial tissue to migrate into the defect ${ }^{1}$. However, care should be taken during placement because exposure of the membrane during the healing of the bone defect can lead to significant a decrease in bone tissue regeneration ${ }^{9}$.

In dentistry, GBR is commonly understood as a surgical technique to improve bone defect in a particular region through new bone formation. This technique is based on Melcher's ${ }^{10}$ (1970) observation that the type of tissue formed in a given area depends on the type of cells populating that area. Therefore, the aim of GBR to exclude soft tissue with the use of barriers in such a way that only bone cells populate the region to be regenerated. Dahlin et al. ${ }^{11}$ (1988) was the first to demonstrate that bone defects created on mandibles of rats can be healed successfully using GBR procedures. GBR has been accepted as an excellent option for periodontal treatment and, after several decades of use, the advantages and disadvantages of this technique are already well known.

Non-absorbable membranes show good results when used in large bone defects ${ }^{12}$. Murray ${ }^{13}$ (1957) placed plastic domes in the iliac and femoral regions of dogs, noting that the entire areas were filled with blood clot and consequently bone tissue. Philips ${ }^{14}$ (1990) reported that the new bone is formed only where there is biomechanical stability of the membrane, that is, the membrane should be well fixed and remain stable as micro-movements may influence the type of tissue to be formed. Bartee ${ }^{15}$ (2001) have stated that one of the benefits of the use of occlusive membranes is that there is less bone resorption in the early stages of healing, but the mechanism responsible for this result is not very clear.

Latex membrane is the result of biotechnological development and is available as a thin, translucent elastic, easy-to-use biomembrane originated from natural material (latex polymer extracted from plants). Its structure is composed of polyisoprene chains and proteins, so like the cell membranes. The latex membrane has a microarchitecture that allows protein and cellular adhesion as well as stimulation of the various cell types adhered, in particular the macrophages involved in the healing process. The analysis of the micro-geometry of the latex membrane surface at 50- and 500-fold increases reveals a "lunar surface" appearance, and examination by scanning electron microscopy at 1500-fold increase confirms the existence a rough exterior with recesses and protrusions. These structures have an important role in the processes of cell adhesion and maintenance of vascularization of tissue-interface membrane of the fibrous capsule, which begins when the latex membrane is applied on the implanted tissue. It has great plasticity and can be used as a dressing on areas of different sizes, with the advantage of being easily removable.

Frade et al. ${ }^{16}$ (2004) investigated the effect of latex biomembrane to treat leg ulcers compared with the traditional treatment (antibiotic ointments and proteolytic enzymes). Biopsies of the lesion were collected before and 30 days after treatment and subjected to histopathological and immunohistochemical analyses. The result showed that the biomembrane facilitated lesion healing, offering the advantage of a low cost and ease of use. It was also observed that the biomembrane led to a clinical and histopathologic differentiation of tissue healing, with increase in the detection of growth factors, such as vascular endothelial growth factor (VEGF) and transforming growth factor âl (TGFâ1), and reduction of expression of the enzyme inducible nitric oxide synthase (iNOS), compared with controls.

Mrue et al. ${ }^{17}$ (2000) used latex membranes in the treatment of chronic ulcers of different etiologies with 2 to 18 years of evolution by covering the lesions with the membranes every $24 / 48 \mathrm{~h}$. The results showed that from the 3 rd day of treatment, the granulation tissue was clear, becoming lush and full on the 12th day. After granulation, the process of reepithelization occurred at around $75 \%$ of patients quickly and spontaneously. Closure of the lesions with the use of latex membrane ranged from 4 days to about 6 months. In the remaining $25 \%$, despite the formation of granulation tissue, reepithelization was unsatisfactory, and a split-thickness skin graft was used with $100 \%$ success rate.

An important aspect of concern that could influence the success and predictable result in the healing of bone defects is bacterial infection. It has been suggested that immediate postoperative infection in periodontal defects and colonization of membrane surface could be the reason for poor results in some cases. For example, periodontal pathogens can colonize a membrane within $3 \mathrm{~min}$ of intraoral handling. The presence of bacteria on the surface of a membrane in contact with the gingiva 6 weeks after surgery has been shown to affect significantly the gain of clinical insertion. Controlling bacterial colonization in the first stage of healing and reducing the spread of infections can increase the predictability of results ${ }^{18}$.

Occlusive membranes and e-PTFE space promoters have been developed to assist bone regeneration in supraalveolar periodontal defects. Polimeni et al. ${ }^{19}$ (2006) estimated the effect of cell occlusion and space provision by use of membranes on periodontal regeneration. Space-providing occlusive and porous e-PTFE membranes were implanted to 
provide for guided-tissue regeneration in supraalveolar periodontal defects. The gingival ûaps were advanced for primary intention healing that was allowed to progress for 8 weeks. A histometric analysis assessed alveolar bone regeneration relative to space provision by the e-PTFE membranes. The bivariate analysis showed that space provision and membrane occlusivity enhanced signiûcantly bone regeneration. Sites that received the occlusive membrane and those with enhanced space provision presented signiûcantly greater bone regeneration than sites receiving the porous membrane $(p=0.03)$ or exhibiting more limited space provision $(\mathrm{p}=0.0002)$. However, a signiûcant association was found between bone regeneration and space provision at sites receiving occlusive $(b=0.194, p<0.02)$ and porous $(b=0.229 p<0.0004)$ membranes, regardless of the treatment, which means that the relationship between space provision and regeneration was signiûcant for both types of membranes. Regeneration followed similar patterns in both groups. The authors assumed that the healing assisted by these membranes is similar, or at least similarly inûuenced by space provision. However, the magnitude of regeneration was signiûcantly enhanced at sites receiving the occlusive membranes compared with that at sites receiving the porous membrane, when adjusted for wound area. Thus, while space provision appears to be critical for regeneration, membrane occlusivity seems to have adjunctive effects. Although it is not possible to affirm that cell occlusion is an absolute prerequisite for periodontal regeneration, it seems clear that the use of cell occlusive membranes may optimize the magnitude of periodontal regeneration.

The purpose of this study was to compare the use of ePTFE membrane, latex membrane and no biomembrane in the maintenance of the extraction socket, assessing the healing processes and tissue responses caused by membranes.

\section{Material and methods}

The study was approved by the Ethics Committee of the University of Southern Santa Catarina (Protocol number 07.303.4.04III).

Seventeen 50-70-day-old male Wistar rats (Rattus norvegicus albinus), weighing between 180 and $200 \mathrm{~g}$ were kept in individual cages under controlled conditions of lighting (12 h of light/12 h of darkness) and temperature (21 to $25{ }^{\circ} \mathrm{C}$ ), fed a balanced solid diet. The animals were randomly divided into 3 groups: two tests groups using ePTFE membrane (Membrana de Teflon; Bionnovations, Bauru, SP, Brazil) or latex membrane (Biocure; Pele Nova Biotecnologia, Ribeirão Preto, SP, Brazil), and a control group, which did not receive a membrane. The test groups were subjected to GBT surgeries.

The animals were sedated by inhalation of sulfuric ether (Rioquímica, São José do Rio Preto, SP, Brazil) and anesthetized with an intraperitoneal injection of sodium thiopental (Thiopentax; Cristal Pharma Ltda, Contagem, MG, Brazil; $0.2 \mathrm{~mL} / 100 \mathrm{~g}$ body weight). It was used the infiltrating local anesthetic administered mepivacaine $2 \%$ with epinephrine 1:100000 (DFL, Rio de Janeiro, RJ, Brazil).

The maxillary right incisor of each animal was extracted using instruments specially adapted for this purpose. The extraction socket was curetted, gently rinsed with saline and either covered with e-PTFE or latex membranes or left with the blood clot only. Wen placed, the membranes were carefully adapted to the bone margins to avoid migration of the connective tissue into the extraction socket. The periosteum was sutured with 5.0 nylon thread using a 1.5 $\mathrm{cm}$ a needle with a triangular cross section (Techsuture; Techsuture Industria de Comercio de Produtos Cirurgicos LTDA, Bauru, SP, Brazil).

After 30 days of experimental surgical procedures, all animals were sedated by inhalation of sulfuric ether (Rioquímica) and were killed by decapitation. The maxilla was separated from the head and the left maxilla was separated from the right maxilla with the aid of a chisel, by making an incision at the median sagittal plane along the intermaxillary suture. A straight cut was done with a pair of surgical scissors (Hu-Friedy, Chicago, IL, USA) tangential to the distal side of the molars. Samples of the surgical areas were removed in blocks containing alveolar bone and surrounding soft and hard tissues. The blocks were embedded in paraffin and 6ìm-thick longitudinal sections were obtained and stained with hematoxylin and eosin. The sections were viewed with video camera (Sony, DCR-SR42, 40x optical zoom, Carl Zeiss lens, Oberkochen, Germany) and the Image J (Rasband, W.S., ImageJ, U. S. National Institutes of Health, Bethesda, MD, USA) software was used for analyzing histomorphometrically the depth of connective tissue invagination into the extraction socket in millimeters. A first line was traced on the image displayed on the computer screen connecting the buccal and the palatal alveolar crests and, from this line, a second line was traced towards the deepest portion of the connective tissue invagination into the extraction socket. The results were analyzed statistically by analysis of variance $(\mathrm{p}<0.05)$ and Tukey's test for multiple comparison with a significance level of $5 \%$.

\section{Results}

There was statistically significant difference between groups e-PTFE and Latex $(p=0.001)$ and between groups ePTFE and Control $(p=0.012)$, but no statistically significant difference could be found between groups Latex and Control $(p=0.416)$. The mean depths of connective tissue migration into the extraction sockets (in $\mathrm{mm}$ ) of the three groups are presented in Table 1.

Table 1. Mean depths of connective tissue migration into the extraction sockets (in $\mathrm{mm}$ ) of the three groups

\begin{tabular}{lll}
\hline Group & Mean & S.D. \\
e-PTFE membrane & $0.3338^{\mathrm{a}}$ & 0.1267 \\
Latex membrane & $1.866^{\mathrm{bc}}$ & 0.1841 \\
Control (no membrane) & $1.516^{\mathrm{c}}$ & 0.3921 \\
\hline
\end{tabular}

Same letters indicate no statistically significant difference $(p<0.05)$. 


\section{Discussion}

In the present study, the e-PTFE membrane showed better results allowing less migration of connective tissue into the extraction socket, while the protection offered by the latex membrane against connective tissue invagination did not differ significantly from that of the control group (without membrane). This can be explained because the membrane bioabsorbable (latex), in general, increases bone regeneration more than e-PTFE membranes. However, if the dehiscence of the soft tissues does not exist, the e-PTFE membrane allows bone regeneration slightly better than the membrane bioabsorbable. From a clinical point of view, the use of membranes simplifies the management and stabilization of bone-graft substitute materials, but from a biological point of view, the use of barriers promotes a recruitment of defense cells ${ }^{20}$. Frade et al. ${ }^{16}$ (2004) reported that treatment with latex membrane leads the organization of scar tissue consequent to increased production of steam cells. Ereno et al. ${ }^{21}$ (2010) showed that latex membrane accelerated healing in critical bone defects. In another study ${ }^{19}$, porous membranes implanted in supraalveolar periodontal defects were compared with occlusive membranes. It was observed that the occlusion tissue is not an absolute requirement for periodontal regeneration, as the sites that received the membranes showed significant regeneration of cementum, periodontal ligament and alveolar bone, similar to the sites treated with occlusive membranes, which is in accordance with the present study.

In the present study, the e-PTFE membrane showed significantly better results than the control group. In a previous study using a tetracycline-coated e-PTFE membrane, it was suggested that the antimicrobial properties during the initial healing period could result in a gain of clinical integration $^{22}$. The results of the present study are in accordance with those of Schenk et al. ${ }^{23}$ (1994), who assessed the pattern of bone regeneration in canine mandibles using standard and prototype reinforced e-PTFE membranes. After a healing period of 2 and 4 months, the control sites (without membranes) exhibited incomplete bone healing, with a persisting defect, while the test sites (with membranes) presented significantly enhanced bone formation, although bone regeneration was not complete after 4 months. The histological analysis showed that, once activated, bone regeneration progressed in a programmed sequence of maturation steps, which closely resembles bone development and growth pattern.

A limitation of this study is that experimental animal models do not precisely replicate the "in vivo" human conditions, and so further research using different membranes in human patients and with different healing periods is required.

The results of this study demonstrate that treatment with GBR is certainly a successful procedure, when an adequate technique is used. Comparing the two types of membranes, the e-PTFE membrane achieved better results, preventing the migration of tissue into the site of extraction. The latex membrane did not achieve good results in this type of periodontal therapy. Few studies have investigated the use of latex membranes in the treatment of periodontal defects through GBR procedures, needing more studies on this subject.

\section{References}

1. Diès F, Etienne D, Abboud NB, Ouhayoun JP. Bone regeneration in extraction sites after immediate placement of an e-PTFE membrane with or without a biomaterial. A report of 12 consecutive cases. Clin Oral Impl Res. 1996; 7: 277-85.

2. Montanari M, Callea M, Yavuz I, Maglione M. A new biological approach to guided bone and tissue regeneration. BMJ Case Rep. 2013; Apr 9 , 2013. doi:pii: bcr2012008240.

3. Shue L, Yufeng Z, Mony U. Biomaterials for periodontal regeneration: a review of ceramics and polymers. Biomatter. 2012; 2: 271-7.

4. Horowitz R, Holtzclaw D, Rosen PS. A review on alveolar ridge preservation following tooth extraction. J Evid Based Dent Pract. 2012; 12(3 Suppl): 149-60

5. Al Salamah L, Babay N, Anil S, Al Rasheed A, Bukhary M. Guided bone regeneration using resorbable and non-resorbable membranes: a histological study in dogs. Odontostomatol Trop. 2012; 35: 43-50.

6. Matsumoto G, Hoshino J, Kinoshita Y, Sugita Y, Kubo K, Maeda H, et al. Evaluation of guided bone regeneration with poly(lactic acid-co-glycolic acid-co-å-caprolactone) porous membrane in lateral bone defects of the canine mandible. Int J Oral Maxillofac Implants. 2012; 27: 587-94.

7. Scheyer ET, Schupbach P, McGuire MK. A histologic and clinical evaluation of ridge preservation following grafting with demineralized bonematrix, cancellous bone chips, and resorbable extracellular matrix membrane. Int J Periodontics Restorative Dent. 2012; 32: 543-52.

8. Macedo NL, de Macedo LG, Matuda Fde S, Ouchi SM, Monteiro AS, Carvalho YR. Guided bone regeneration with subperiosteal implants of PTFE and hydroxyapatite physical barriers in rats. Braz Dent J. 2003; 14: 199-24.

9. Lekovic V, Kenney EB, Weinlaender M, Han T, Klokkevold P, Nedic M, et al. A bone regenerative approach to alveolar ridge maintenance following tooth extraction. Report of 10 cases. J Periodontol. 1997;68: 563-70.

10. Melcher AH. Repair of wounds in the periodontium of the rat. Influence of periodontal ligament on osteogenesis. Arch Oral Biol. 1970; 15: 1183-204.

11. Dahlin C, Linde A, Gottlow J, Nyman S. Healing of bone defects by guided tissue regeneration. Plast Reconstructive Surg. 1988; 81: 672-6.

12. Walters SP, Greenwell H, Hill M, Drisko C, Pickman K, Scheetz JP. Comparison of porous and non-porous teflon membranes plus a xenograft in the treatment of vertical osseous defects: A Clinical Reentry Study. J Periodontol. 2003; 74: 1161-8.

13. Murray $C$, Holden D, Roachlau W. Experimental and clinical study of new growth of bone in a cavity. Am J Surg. 1957; 95: 385-7.

14. Phillips RW, Jendresen MD, Klooster J, McNeil C, Preston JD, Schallhorn RG. Reports of the committee on scientific investigation of the American Academy of Restorative Dentistry. J Prosthetic Dent. 1990; 64: 74-110.

15. Bartee KB. Extraction Site Reconstruction For Alveolar Ridge Preservation. Part 2: Membrane-Assisted Surgical Technique. J Oral Implantol. 2001; 27: 194-7.

16. Frade MAC, Cursi, IB, Andrade FF, Netto, JC, Barbetta FMB, Foss NT. Management of diabetic skin wounds with a natural latex biomembrane. Med Cutan Iber Lat Am. 2004; 32: 157-62.

17. Mrue, F. Tissue neoformation induced by natural latex biomembrane with polylysine. Application in esophageal and abdominal wall neoformation. Experimental study in dogs [thesis]. Ribeirao Preto: University of Sao Paulo; 2000.

18. Sipos PM, Loos BG, Abbas F, Timmerman MF, van der Velden U. The combined use of enamel matrix proteins and tetracycline-coated expanded polytetrafluoroethylene barrier membrane in treatment of intra-osseous defects. J Clin Periodontol. 2004; 32: 765-72. 
19. Polimeni G, Koo K-T, Qahash M, Xiropaidis AV, Albandar JM, Wikesjo" UME. Prognostic factors for alveolar regeneration: effect of tissue occlusion on alveolar bone regeneration with guided tissue regeneration. J Clin Periodontol. 2004; 31: 730-5.

20. Hämmerle CHF, Jung RE. Bone augmentation by means of barriers membranes. Periodontol 2000. 2003; 33: 36-53.

21. Ereno C, Guimarães SA, Pasetto S, Herculano RD, Silva CP, Graeff $\mathrm{CF}$, et al. Latex use as an occlusive membrane for guided bone regeneration. J Biomed Mater Res A. 2010; 95: 932-9.

22. Zarkesh N, Nowzari H, Morrison JL, Slots J. Tetracycline-coated polytetrafluorethylene barrier membranes in treatment of intraosseous periodontal lesions. J Periodontol. 1999; 70: 1008-16.

23. Schenk RK, Buser D, Hardwick WR, Dahlin C. Healing pattern of bone regeneration in membrane-protected defects: a histologic study in the canine mandible. Int J Oral Maxillofac Implants. 1994; 9: 13-29. 